\title{
La transversalidad del color y su papel comunicador en las imágenes visuales, de la literatura a la imagen actual del cuento clásico Blancanieves
}

\begin{abstract}
Resumen
Este artículo se enfoca en el análisis de la transversalidad como elemento característico en el uso del color como signo-plástico en las imágenes visuales; permitiendo una narrativa más completa en las diferentes versiones y usos del color de un mismo tema. Para lograr este objetivo se utilizará como referente el cuento clásico de Blancanieves, mostrando los diferentes usos del color en el cuento y la transversalidad en ellos. Este análisis hace parte de la investigación "El color como medio narrativo en la ilustración de cuentos clásicos: Blancanieves y Alicia en el país de las maravillas", donde se trabaja el color como signo-plástico y por lo tanto con valor narrativo dentro de las imágenes visuales, que tiene como objetivo poder identificar las características y rasgos del color que permiten una narrativa visual. Para poder profundizar sobre el tema, uno de los puntos trabajados se centra en la transversalidad del color; del texto a la imagen, donde se pretende establecer si hay relación entre el uso del color en los escritos de los cuentos clásicos y el uso del color como signo plástico en las imágenes resultantes de los mismos. Este análisis se realizó por medio del diálogo con diferentes autores del medio y análisis bibliográfico, que dieron como resultado final la propuesta de la existencia de la transversalidad del color como una de las características que determina el carácter narrativo del color en las imágenes visuales. Pudiendo ser esta la base para profundizar en el análisis y uso del color como signo-plástico y, por lo tanto, ente narrativo en las artes visuales.
\end{abstract}

\author{
Jeice Hernández \\ Candidata al Doctorado en Arte: \\ Producción e Investigación de la \\ Universidad Politécnica de Valencia \\ Valencia, España \\ Correo electrónico: \\ jeiceherco@doctor.upv.es / info@ \\ jeicehernandez.es \\ ๑ orcid.org/0000-0002-1486-1333 \\ Google Scholar
}

Recibido:julio 20 de 2018 Aprobado:junio 05 de 2019

\section{Palabras clave:}

Artes visuales, color, cuentos clásicos, signo-plástico, transversalidad. 


\section{The transversality of color and its communication role in visual images, from literature to the current image of the classic story Snow White}

\begin{abstract}
This article focuses on the analysis of transversality as a characteristic element in the use of color as a plastic-sign in visual images allowing a more complete narrative in the different versions and uses of color in the same topic. To achieve this objective, the classic story Snow White and the Seven Dwarves is used as a reference showing the different uses of color in the story and their transversality. This analysis is part of the research project "Color as a narrative means in the illustration of classic stories: Snow White and the Seven Dwarves and Alice in Wonderland" where color is worked as a plastic sign and therefore with narrative value within the visual images which aims to identify the characteristics and color features that allow a visual narrative. In order to go deeper into the subject, one of the points worked focuses on the transversality of color from the text to the image, where it is intended to establish if there is a relationship between the use of color in the writings of the classic stories and the use of color as a plastic sign in the images resulting from them. This analysis was carried out through dialogue with authors of the medium and bibliographic analysis which resulted in an approach to the concept of transversality of color as one of the characteristics that determines the narrative character of color in visual images. This could be the basis for deepening the analysis and use of color as a plastic sign and, therefore, a narrative entity in the visual arts.
\end{abstract}

Key words:

Classic stories, color, plastic sing, transversality, visual arts. 


\section{Introducción}

Los cuentos clásicos nos enseñan y acompañan a lo largo de nuestra infancia, se convierten en nuestra guía social, cultural y visual, aprendiendo a través de ellos cómo debemos ver y comportarnos en el mundo, son nuestra guía en un mundo de sombras Ilenos de historias, esfuerzos y esperanza. El cuento se convierte en un elemento transformador de nuestras vidas, nutriendo nuestro mundo visual y sus significados. "...colores y sentimientos no se combinan de manera accidental (en las imágenes) sus asociaciones no son cuestiones de gustos, sino experiencias universales profundamente enraizadas desde la infancia en nuestro lenguaje y nuestro pensamiento" (Heller, 2000, p. 17). A partir del s. XIX, el color forma parte inseparable de las imágenes impresas, lo que representa una apertura más al mundo cromático, el significado y relación con aquello que nos rodea se ve totalmente influenciado por el color y la manera en que lo percibimos.

En la actualidad el color en las imágenes se vuelve esencial en la manera que entendemos el mensaje de las mismas, "Cada obra de arte expresa su mensaje a sus contemporáneos no solo por lo que contiene sino por lo que deja de contener." (Gombrich, 1994, p. 18). Aunque Gombrich se refiere a los elementos que se van enfrentando, heredando o referenciando de los siglos y técnicas pasadas, esta frase también nos sirve en otro contexto relacionado con el uso del color en las imágenes: Un ejemplo de esto lo podemos ver en el Guernica, una obra donde las conjunciones de signos pictóricos logran transmitir el horror y la tragedia ante un hecho histórico. Hablar de color en este ejemplo no parece lo más adecuado ya que todo el cuadro está construido a base de blanco, negro y gris; desde lo físico y científico existiría una gran réplica al hablar de color en esta obra, puesto que está demostrado que el blanco y negro, aunque los relacionamos con la gama cromática, no los definimos dentro del espectro del color como tal, sino que están relacionados con una consecuencia de la suma o resta de los mismos. 
Sin embargo, desde el ámbito plástico hablar de color en el Guernica toma otra perspectiva; ya que el color en las obras gráficas y plásticas posee otro tipo de relación con el espectador, no se toman desde una visión científica o física, sino, desde su significado como signo plástico, donde las características sémicas y plásticas se unen para generar un sentido y forma a aquello que estamos viendo; es por esto, que al ver el Guernica no solo vemos un cuadro en blanco y negro o escala de grises sin color, sino que, son precisamente estos los que terminan de dar sentido a obra; el efecto del no color en una época donde el color determina la visión del mundo, crea un impacto y un ambiente ante los ojos del espectador (hablando de estímulos visuales) donde la falta del color enfatiza los grises, negros y blancos, termina de dar fuerza expresiva a la obra, enfatizando desde el no color la tristeza, el dolor, la desesperanza y el contraste entre la vida y la muerte; valores sémicos que atribuimos al uso de estos tonos en las imágenes. Al final todo se basa en la narración, el cómo contamos la historia influye notablemente en la manera de percibirla y el color es parte de ella.

En la actualidad sabemos que el uso del color marca la diferencia en cómo percibimos una imagen ${ }^{1}$, lo que constantemente es explotado por el cine y medios visuales para enfatizar o manipular una narración hacia cierto significado, el mundo cromático en que nos desenvolvemos determina nuestra forma de interpretación del mismo, haciendo que una imagen carente de color tenga un significado distinto, no es lo mismo pensar en una imagen en blanco y negro, que leerla desde el no color, donde el significado e impacto es totalmente diferente. En la versión de Pablo Berger (2012) de Blancanieves, el no color es usado para identificar una época pasada, sin embargo, las referencias al color son constantes, la más evidente es al color rojo; al igual que en el cuento, la película utiliza diferentes elementos que nos recuerdan el color

'Se habla de imágenes como una unidad estática, teniendo en cuenta que las imágenes de video, cine y medios visuales en movimiento se basan en imágenes separadas que al unirse crean la sensación e movimiento. 
rojo, los labios, el vino, la sangre, el capote para el toro; son elementos cuyo color característico nos hace inevitablemente pensar en rojo. Si pensáramos en la película originada desde el blanco y negro no sería evidente para nosotros el rojo en ella, sin embargo, en la época actual, es inevitable leerla desde el no color donde la referencia cromática existe, aunque no la veamos.

La narración obedece a un relato oral o escrito que cuenta una historia de hechos ficticios o reales. Existe una relación entre el "movimiento" de la historia (donde se presenta una continuidad de los hechos y acción de los personajes que ayudan a desarrollar la historia) y el concepto de narración. Sin embargo, al hablar de ilustraciones o imágenes debemos también hablar de narrativa visual, la cual según Barton (2016) obedece a un alto nivel de 'alfabetización visual' que se ha desarrollado durante el mundo contemporáneo. Es por medio de esa narrativa visual, que el lector es capaz de obtener sentido de las páginas que cuentan con imágenes (p. 98).

Esta narrativa visual plateada por Barton se da desde los propios elementos o signos pertenecientes a la imagen, es la relación e interpretación de estos signos, la que genera un significado o asociación y le da sentido a la misma por parte del espectador. Como se mencionó anteriormente el color hace parte de estos signos visuales, más específicamente es catalogado dentro de los signos plásticos por su relación con la estética y expresividad de la imagen por lo que hace parte del plano expresivo de la misma.

Hoy en día al hablar de color podemos referirnos a él de cuatro maneras: como luz, pigmento, sensación, como signo (portador de significado e información). En realidad, y aunque se puede estudiar o definir desde esas cuatro visiones constantemente estamos usando todas ellas para definir el color. Actualmente, al considerar el color como signo-plástico tenemos en cuenta sus características propias definidas en tono, luminosidad y saturación, además su capacidad de 
asociación, transmisión, contraste, creación de armonías y su parte material o expresión. Estudiar el color resulta casi imposible, realizar una separación de sus cualidades, propiedades, características, usos y relaciones, sería equiparable a despojarlo de todo aquello que le da significado. Por lo tanto, el tema se vuelve prácticamente inabarcable, al igual que el color el estudio del mismo resulta ser bastante inestable como para poder delimitarlo o encajarlo dentro de un concepto o idea.

Aunque existen múltiples maneras de abarcar el color para poder comprender lo que el paso de un medio a otro del mismo conlleva, en este estudio se toma el color (al igual que lo plantea Goethe en su teoría de los colores, Carrere y Saborit, en el libro Retórica de la pintura y Heller en el libro Psicología del color, ) como portador de significado, adquirido por la sociedad, heredado desde los comienzos y que marca nuestra visión y percepción del mismo. Analizándolo desde sus características de signo plástico (elemento significante con características de forma y contenido) y ente narrativo en las imágenes del cuento clásico de los Grimm Blancanieves, para así determinar la existencia de una narrativa cromática que pasa del texto a la imagen ilustrada de este tipo de literatura en particular.

Apartándonos entonces de la concepción del color como herramienta supeditada a la forma y al uso del marketing donde el color es usado con la intención de atraer e incentivar a las personas para cumplir un objetivo de mercado.

\section{Metodología}

La metodología a utilizar se basa en la recolección de datos por medio de textos e imágenes al hacer referencia a textos literarios como artísticos y a imágenes relativas o ilustraciones, se trabaja desde una metodología mixta donde se 
unen elementos cuantitativos trabajado a través de entrevistas y cualitativa con respeto al análisis de resultaos, centrada en el método hermenéutico analógico, realizando un análisis crítico y deductivo contrastando la información a medida que se realiza la recolección de la misma.

Dentro de este concepto de análisis se tomaron en cuenta textos como los de Batchelor (2000), Groupe $\mu$ ( 1993), Grupo Mañana (2016), entre otros, realizando un análisis del color desde sus características sémicas llevando estos resultados a la práctica por medio de ejercicios de color que más adelante servirían para detectar ciertos elementos en las imágenes seleccionadas.

Como primera medida y por la poca información al respecto del tema en específico, para poder profundizar en el tema de investigación desde el área literaria, se contactó con expertos en literatura, narrativa visual y folklor del siglo XIX, contando con la retroalimentación de Zipes (Comunicación personal, 12 de abril 2018) y Alzate (Comunicación personal, 23 de octubre 2018), para de esta manera poder tener referentes bibliográficos confiables que ayudaran a profundizar en el tema. Igualmente se analizaron diferentes teorías del color entre ellas la de Chirimuuta (2017) de la cual se toma su teoría adverbialista del color como uno de los elementos básicos del estudio, logrando establecer un punto de partida conceptual que permitiera analizar el color dentro de las imágenes ilustradas de los cuentos clásicos.

Se procedió entonces a analizar el color en imágenes del cuento de Blancanieves para lo que se tuvo en cuenta la variedad o pluralidad de funciones narrativas del color en estas imágenes al igual que la variedad de técnicas utilizadas. Por esta razón se tomaron autores que no solo manejaban técnicas diferentes, sino que fueran de épocas distintas para así determinar si se mantenían o no ciertos elementos narrativos-cromáticos dentro de la imagen. 
Se tomaron entonces tres variables donde se unía el análisis del color como signo-plástico en las imágenes, el color como ente activo dentro de las mismas y la relación del color con la literatura originaria de estas historias, para poder realizar un análisis completo del color en este tipo de imágenes.

\section{De los cuentos clásicos, el color y Blancanieves}

Para muchos es conocido que los cuentos clásicos tienen su origen en la tradición oral, los primeros hallazgos literarios de este tipo de historias datan desde el s. $\mathrm{XVI}$, y eran correspondientes a historias o relatos recopilados por folcloristas medievales; según Gaster (1931), el autor Giambattista Basille recopiló a comienzos del XVII en el libro Pentamerone, historias procedentes de la cultura popular que se han mantenido hasta la actualidad como La cenicienta, La bella y la bestia o El gato con botas (pp. 496-500). Los cuentos hasta este momento tenían un carácter más instructivo y normativo, se trataba de mostrar tanto a niños como adultos lo que se debía hacer o no, en ciertas situaciones. Es a finales del s. XVII y a partir del s. XVIII que en Europa se comienza a ver la infancia con otros ojos dentro de la sociedad, centrándose más en ella y su papel dentro de la misma, protegiendo la niñez y lo que representaba, aunque este no es el único punto de vista; algunos consideran que en realidad lo que cambió es la visión sobre cómo podía ser útil la infancia para la sociedad de la época (sin que esto representara un trato especial ni cambio con respecto a sus condiciones); lo que sí es cierto es que se comienzan a establecer cambios en la literatura infantil y en el concepto de enseñanza, haciendo entonces que las historias o cuentos infantiles tomen gran relevancia, no solo como medio de aprendizaje sino como halo de esperanza para las nuevas generaciones.

Los cuentos de mamá oca de Charles Perrault (1697) introducen a la sociedad historias como la de Piel de asno, Caperucita roja o Pulgarcito, con una moraleja al final de la historia marcando una diferencia clara entre la literatura anterior y 
la que se estaba presentado en esta época. A partir de este momento los cuentos infantiles fueron evolucionando y dirigiéndose más hacia un público más infantil que adulto, suavizando algunas versiones y cambiando varios desenlaces. En el s. XIX las recopilaciones folclóricas tenían ya como fin el enseñar y transmitir valores para la vida, este sentido en particular hacía que los elementos en la historia (en los que incluimos el color) tomaran gran relevancia, ya que su fin no era entretener sino enseñar. La forma en que se usan los colores en este tipo de historias caracterizan y definen ciertos conceptos al lograr enfatizar ideas dentro de la propia narrativa del cuento, este es el caso en particular del papel de color rojo en los cuentos clásicos según lo plantea Pastoureau (2017), quien usa el cuento de caperucita roja para ejemplificar cómo este color es socialmente identificado y puede llegar a ser relacionado dentro de la historia, con peligro, seducción, sexo y con características místicas de protección.

Es precisamente en este siglo que se publican los cuentos de los Grimm donde se encuentra la versión de Blancanieves que se toma para este análisis. Uno de los elementos a tener en cuenta de este cuento es el momento en que es presentado, ya que el fin "pedagógico" del mismo le da un valor narrativo particular a los elementos que se presentan en la historia, igualmente se tomó en cuenta que en esta historia las referencias cromáticas no solo hacen parte de la narrativa y significado sémico, sino que como se verá más adelante, se cuenta por medio de éstas la propia historia.

Carolina Alzate, profesora de la Universidad de los Andes en Colombia, experta en la literatura del siglo XIX y en narrativa visual, recientemente habló en una entrevista sobre los diversos elementos que aparecen en la literatura, y en las narrativas en general. Señaló que ninguno de ellos aparece de manera gratuita y que el color en ellos, por ejemplo, está ligado a los contextos folclóricos y culturales de cada obra, contextos amplios en el tiempo. Añadió que, de esta manera, en los estudios literarios actuales se les da más importancia a esos contextos al leer un libro que a la visión personal del autor, pues esta "se lee dentro de una tradición"; así pues, al observar las imágenes actuales de esos escritos nos encontramos frente a signos culturales compartidos provenientes no solo de la tradición literaria sino también de la tradición pictórica, por ejemplo. (Comunicación personal, 23 de octubre) 
El color de las ilustraciones de estas historias es usado como identificador, el cual transmite características culturales y sociales que son evidentes dependiendo del conocimiento del contexto, uso y sentido del mismo; así mismo hay que tener en cuenta que "El color como medio comunicativo e identificador dentro de la imagen se ha caracterizado como un elemento sémico de la misma, de esta manera es un recurso esencial para el aprendizaje y el esfuerzo comunicativo de la información" Becerra, Hernández y Pérez (2019, p.340). El valor del color dentro de las imágenes como se ha planteado hasta ahora se presenta de diferentes maneras, lo cual se hace más fácil de comprender si consideramos este elemento desde un punto de vista más activo, en el que el color posee una narrativa propia que se mantiene al pasar de un medio a otro, planteando entonces una transversalidad del color donde sus características sémicas se evidencian en el uso del color como signo-plástico en las ilustraciones o imágenes visuales de estas historias presentes en el tiempo.

\section{La elección de la historia}

La elección del cuento de Blancanieves para esta investigación se dio por tres razones principales:

1. Constante referencia al color en los cuentos originales: este cuento posee una constante referencia al color, a lo largo de toda la historia, lo que nos permite establecer de manera más clara el papel y significado del color dentro del relato.

2. Impacto en la cultura visual: es una historia que ha generado impacto en la cultura y el arte visual durante más de un siglo. Desde que se publicó Blancanieves influyó e inspiró a diferentes artistas relacionados con las artes visuales (cineastas, pintores escultores, dibujantes, etc.). Esto dio lugar a diferentes versiones ilustradas del cuento que se fueron extendiendo y 
adaptando a través del tiempo, con la particularidad de que fueron los mismos escritores los que comienzan a generar cambios en los escritos, adaptándolos y creando nuevas versiones de la historia. La popularización de las ilustraciones comienza a tomar fuerza al ser adaptadas para un público infantil, ya que las imágenes tomaban en este caso gran relevancia en el cuento, lo que generó a través del tiempo múltiples versiones visuales que abarcan todo tipo de géneros, técnicas y variaciones; Igualmente, el hecho de que Disney eligiese este cuento para convertirlo en su primer largometraje animado, convirtió a las imágenes del mismo en un referente visual, dentro de la cultura popular, generando nuevas versiones de imágenes de la historia.

3. Variedad: es un cuento que debido a su impacto cultural se puede encontrar en múltiples formatos, variaciones y adaptaciones visuales, tales como: videojuegos, musicales, ballets, animes, series de televisión, parodias, dibujos animados, revistas, cuentos, pinturas, etc. Así se genera un gran abanico de ilustraciones sobre la historia y el personaje de Blancanieves, que nos permite poder tener una visión más real del papel del color en las mismas.

\section{El color y su transversalidad}

Otálora y Hernández (2018) expresan lo siguiente con respecto a la obra de arte, ya sea un cuadro, una ilustración o un objeto: "El arte tiene la particularidad de relacionarse con las personas desde un punto de vista más sensorial, no conceptual" (p. 236). Esta idea planteada por Otálora y Hernández no se aplica al hablar del color en los cuentos clásicos; lo interesante del color en las ilustraciones e imágenes de cuentos clásicos es que está presente tanto en la narración textual como en la visual donde en esta última, al existir una conexión con el texto se terminan uniendo estas dos cualidades sensoriales y 
conceptuales en una sola lectura complementándose para generar una sola narrativa para el espectador.

Ya sea exacto o no el uso del color en el texto y en la imagen, lo que sí podemos determinar es que el uso de este, en las dos, trabaja de manera similar: como identificador, dándole significado a ciertos elementos que los caracterizan y enmarcan dentro de un sentido social y cultural. La imagen originada de este tipo de cuentos posee además de una narrativa visual, una narrativa heredada del texto; aunque no entran dentro de una secuencia de movimiento (visto como hilo de una historia continua que se presenta en diferentes estadios), la imagen resultante al crear una relación directa con una historia secuencial, termina siendo un fotograma (un zoom a una parte específica de la historia), adquiriendo entonces parte del movimiento de la misma. Esto hace a los cuentos clásicos ideales para ejemplificar la transversalidad del color y su uso como signo al pasar a la imagen visual.

Igualmente, se pueden encontrar referencias en la literatura, en las que claramente el color trabaja como signo, donde sus características propias de sentido y forma se unen para transmitir una idea en particular, lo que le da relevancia a la hora de interpretar y leer las imágenes sacadas o basadas en los cuentos clásicos. Esto se puede evidenciar en el libro de Nikolajeva (2014), Retórica del personaje en la literatura para niños, que trata las diferentes características de algunos personajes con relación al color; por ejemplo, para el caso de Ana Shirley, protagonista de Ana de las tejas verdes, los colores reflejan su estado de ánimo o emociones dependiendo del momento que esté viviendo dentro del cuento, así mismo, cambian en el momento en que el personaje evoluciona o pasa de un momento a otro dentro de la historia. La autora hace evidente la importancia del color para la narrativa como símbolo e instrumento que describe el desarrollo del personaje. 
Una de las referencias más recientes al color en las ilustraciones de cuentos clásicos la encontramos en Mavor (2017), la autora hace varias comparaciones entre ilustraciones o referentes visuales que tenemos de ciertos momentos del desarrollo de los cuentos clásicos y elementos sacados de la realidad, que conectan las historias y sus versiones con momentos sociales e históricos específicos; una de sus comparaciones está relacionada con el cuento de Blancanieves donde se presenta una comparación de la niña acostada en el ataúd de vidrio con incrustaciones de oro, como si estuviese atrapada en un daguerrotipo, "preciosos y únicos objetos eran generalmente guardados en cajas con ornamentos, incluyendo cajas de oro y marcos, guardados bajo vidrio. Mejillas y labios eran algunas veces coloreadas a mano con rojo (2017, p. 121) (figura 1).

Se establecen varias relaciones cromáticas desde el color amarillo oro, el negro tierra y el rosado de las mejillas: Según explica la autora St. Clair (2016) en su libro The secret lives of color en la actualidad reconocemos el color oro como símbolo de deseo y estatus, el negro está relacionado con los finales y los comienzos (significado muy utilizado en los cuentos clásicos para narrar el paso a los otros mundos y la transformación o evolución del héroe, según lo plantea Propp (1998)) y el rosado de las mejillas se relaciona, como bien lo plantea Mavor, con la vida; cuando leemos el pasaje de los Grimm sobre la muerte de Blancanieves nos damos cuenta que precisamente estas referencias de color son las que terminan de dar sentido a la escena y podemos entender mejor lo que sucede en ella:

Después quisieron enterrarla, pero al ver que seguía tan lozana como una persona viva, y que sus mejillas seguían tan rosadas y hermosas, dijeron:

-No podemos sepultarla en la negra tierra-. Así que mandaron construir un ataúd transparente, de cristal, que permitía verla desde cualquier lado, la pusieron dentro y escribieron con caracteres de oro su nombre y su condición de princesa. (Hermanos Grimm, 2000) 


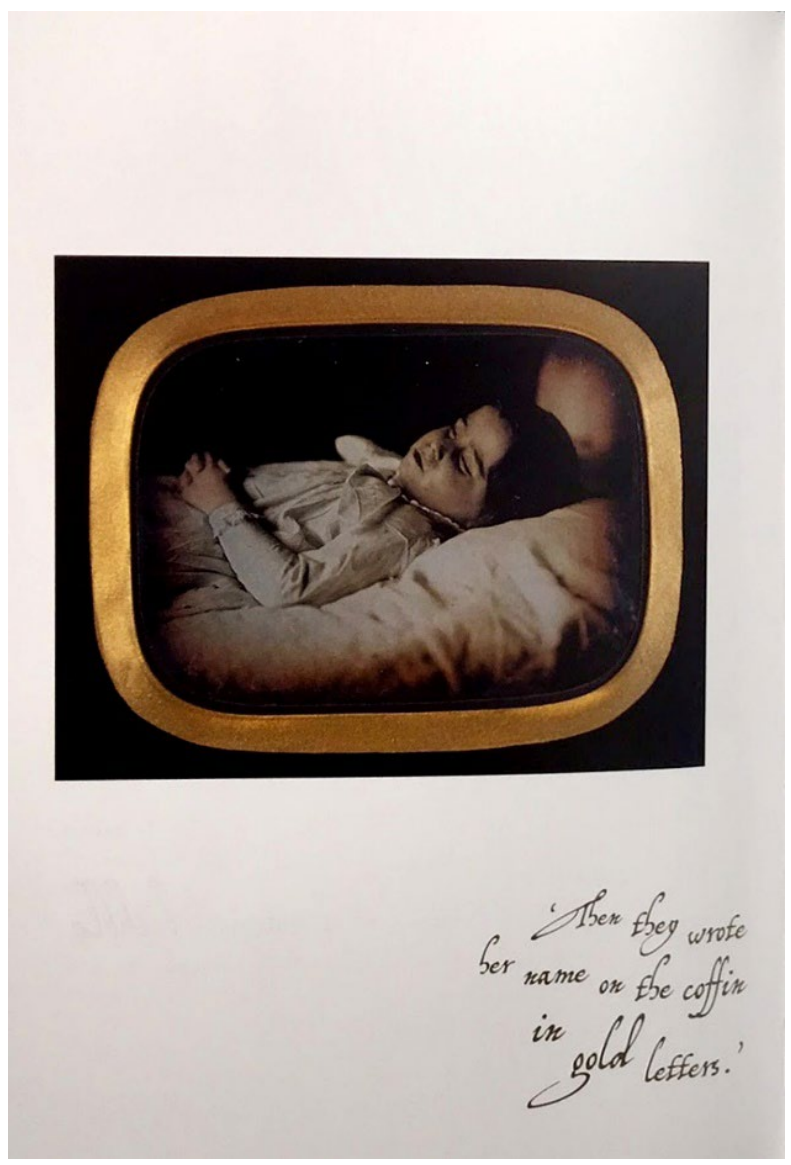

Figura 1. AURELIA: Art and Literature through the Mouth of the Fairy Tale. P. 120. Fuente: Imagen tomada de Mavor (2017). 
Es precisamente ese significado y la expresión del color, que tienen que ver con las lecturas contextuales e intertextuales de los momentos en que se crean las imágenes, en los que se basa gran parte de esta investigación. Siendo conscientes de que, así como algunas de las ilustraciones fueron hechas teniendo en cuenta los diferentes elementos y el sentido que tenían estas historias en sus versiones originales y sus cambios en la actualidad con referencia al color, también existen versiones e ilustraciones que no fueron hechas con ningún tipo de rigor relacionado con el sentido ni objetivo de la historia original ni con el intertexto o contexto del color alrededor de la imagen generada por ella.

A lo largo de la historia de Blancanieves podemos encontrar una constante referencia al color rojo, algunas veces mencionado directamente y otras por asociación; éste lo podemos encontrar en la descripción de la niña, en la encomienda al cazador cuando la reina pide los pulmones y el hígado de Blancanieves, en el vino, en los 7 enanitos cuando habla de las piedras preciosas, en la manzana, y finalmente en el castigo de la madrastra donde la obligaron a usar: unos zapatos al rojo vivo y a bailar hasta caer muerta. Si tomáramos estas referencias en una secuencia como en una película de cine, el color rojo cumpliría sin lugar a dudas con un papel narrativo donde su constante presencia crea una secuencia para el espectador que permanece en el tiempo y finalmente muestra la evolución de la historia, desde el nacimiento de la niña, hasta el final del cuento. Igualmente existe la presencia de otros colores descriptivos que dan significado a la imagen del cuento: cuando la reina se entera de que Blancanieves es la más bella, se puso amarilla y verde de envidia. Dentro de la significación de los colores en esta época el verde estaba relacionado con la maldad, brujería y muerte, (esto debido al origen del mismo), lo que de alguna manera estaba augurando los siguientes acontecimientos de la historia. 
Hablando específicamente del cuento de Blancanieves encontramos básicamente dos diferentes referencias al manejo del color del cuento que han estado presentes a lo largo de la interpretación de esta historia, la primera de ellas está relacionada con los estadios que deben pasar los personajes para su evolución dentro de la historia, y una segunda relacionada con el ámbito sexual.

Propp (1984) plantea que los diferentes elementos del cuento giran en torno a rituales y diferentes métodos de iniciación sacados de estructuras socioeconómicas antiguas, y llevados con transformaciones y cambios al cuento. Según el planteamiento del autor, la sangre (mencionada al comienzo del cuento) haría parte de un ritual donde no es, hasta que este elemento identificado por el color rojo entra en escena que comienza la historia:

\begin{abstract}
Un día en la mitad del invierno, cuando los copos caían del cielo como plumas, una reina estaba sentada junto a una ventana cuyo marco era de ébano. Y mientras cosía, alzo la vista para mirar los copos y entonces se pinchó el dedo con la aguja y tres gotas de sangre cayeron en la nieve. Dado que el rojo lucía tan hermoso sobre la blanca nieve ella pensó: "¡Si tuviera un hijo tan blanco como la nieve, tan rojo como la sangre, tan negro como la madera del marco!" Poco tiempo después tuvo una hija que era de piel tan blanca como la nieve, de labios tan rojos como la sangre y de cabellos tan negros como el ébano, por lo cual fue Ilamada Blancanieves. Pero al nacerla niña, murió la reina. (Grimm, J. \& Grimm, W. 1976)
\end{abstract}

Bettelheim (2012) en cambio habla del color rojo como referente sexual y medio para introducir al niño lector en lo que a esto se refiere:

La historia comienza cuando la madre de Blancanieves se pincha un dedo y tres gotas de sangre resbalan sobre la nieve. Aquí se indican ya los problemas que plantea la historia: la inocencia sexual y la pureza contrastan con el deseo sexual, simbolizado por la sangre roja. Los cuentos de hadas preparan al niño para que acepte un hecho todavía más traumático: la hemorragia sexual como en la menstruación o, más tarde, en la relación sexual cuando se rompe el himen. Al oír las primeras frases de "Blancanieves", el pequeño descubre que el hecho de sangrar — tres gotas de sangre (tres porque es el número que, en el inconsciente, está más íntimamente relacionado con el sexo)— es una condición previa para la fecundación, pues precede necesariamente al nacimiento de un niño. 
En este caso, la hemorragia (sexual) está ligada a un suceso «feliz»; sin otras explicaciones más detalladas, el pequeño aprende que ningún niño —ni tan sólo él— puede venir al mundo sin que se dé antes esta hemorragia. (Bettelheim, 2012, p. 238)

\section{Ilustración e imágenes visuales}

Hoy en día enmarcados en la realidad de la cuarta revolución industrial donde las telecomunicaciones y su uso exponencial son una de sus principales características (Becerra et al., 2018, p. 177), el manejo del color en las ilustraciones o imágenes visuales en los cuentos clásicos como en los diferentes temas usados en los medios de comunicación es heterogéneo, ya que el manejo de éste ha evolucionado sumando nuevos medios que dan como resultado imágenes mixtas, digitales o interpretaciones llevadas a otros medios artísticos, siendo precisamente el medio el determinante del manejo del mismo, la técnica de aplicación del color varía según el artista y forma de reproducción, lo que inevitablemente cambia a ojos del espectador su significación.

Teniendo en cuenta lo anterior podríamos concluir que el uso del color en las imágenes comunicativas es tan variado como los autores de las mismas. Sin embargo y aunque esto podría ser cierto, estos estilos de uso del color se pueden enmarcar bajo dos tendencias en cuanto a ilustraciones e imágenes de cuentos clásicos se trata: una que obedece a una evolución mental y temporal dándole nuevos significados y manejo a los elementos del cuento, y otra donde la imagen y sus elementos están supeditados totalmente al texto.

Un expositor de la primera tendencia es Jack Zipes, folklorista y gran conocedor de estas historias. Plantea que existe una evolución en las diferentes versiones y manera de abordar los cuentos clásicos haciendo referencia a las sutiles y no tan sutiles transformaciones de estos, atribuyendo los cambios interpretaciones y manejo de los elementos de las mismas (dentro de los que incluimos el 
color) a los cambios socio culturales, y los diferentes mensajes que se quieren transmitir a través de las nuevas versiones (Zipes, 2014). Zipes plantea una evolución no solo de los cuentos si no de su narrativa visual, la cual según lo plantea el autor obedece a los cambios de cada época, siendo esto evidente en el manejo de los elementos visuales y literarios que contiene la historia.

Con respecto a la segunda categoría John Harthan, en su libro Historia del libro ilustrado plantea dos usos básicos del color con relación a las ilustraciones, un primer grupo que se refiere a las ilustraciones de cuentos clásicos, donde el color es usado como una herramienta supeditada al resto de elementos que contenía la imagen, la mayoría de las veces a la línea (1981). El segundo grupo lo enfoca a libros más científicos y técnicos donde el color cumple una función específica de ilustrar algo real.

Desde el punto de vista de esta investigación, la visión de Hartan es bastante sesgada, ya que habla desde un mundo donde la ilustración literaria es entendida como aquella que no domina el texto, sino que lo acompaña, sin ninguna aportación significativa. Por el contrario, la visión de Zipes es mucho más acertada desde nuestro punto de vista, y es precisamente desde esta perspectiva que se trabaja el color en las imágenes dentro de esta investigación.

Para la comprensión de la transversalidad del color en las imágenes visuales de los cuentos clásicos, hace falta entender sus relaciones, temporalidad y autores tanto de creadores como observadores que le dan vida a la imagen.

\footnotetext{
Si estamos de acuerdo con Marshall McLuhan de que el medio es el mensaje, de que las técnicas en las que se ilustran y reproducen los libros son la razón de su existencia (de la ilustración), solo deberíamos preocuparnos en qué tan efectiva es la pintura, o el color en su efecto psicológico, o que tan precisa es la representación anatómica del dibujo. Pero en los libros para niños, el medio no es el mensaje. La expresión creativa del artista en relación con la experiencia creativa del niño es el mensaje. (Kingman Lee et al., 1968, Introducción)
} 
En definitiva, el uso del color y su lectura como referente cultural, se ven afectados por las relaciones contextuales e intertextuales presentes en su creación y lectura.

El ejemplo más evidente de transversalidad se puede encontrar en la manzana que se volvió prácticamente símbolo del cuento: la manzana envenenada, caracterizada por el color rojo que como hemos visto dentro de la historia de Blancanieves está relacionado con la transición de un estado a otro, sangre, peligro y objeto de deseo, reúne los diferentes significados lográndolos concentrar en un solo objeto; no podemos obviar que la manzana por sí sola también tiene un significado histórico, donde ejerce como objeto de deseo, tentación y castigo o agravio ${ }^{2}$, otras veces es relacionada con benevolencia y sabiduría e inmortalidad, es por esto que es precisamente el uso del color el que termina de darle el sentido definiendo su papel dentro del cuento, convirtiendo la manzana en un objeto con un significado especifico y característico dentro de la historia "por afuera se veía apetitosa, blanca con una mejilla roja, de modo que todos los que la vieran la anhelarían; pero quien comiese un trozo de ella seguramente moriría". (Grimm, J. \& Grimm, W. 1976)

Según Zipes (2014), la artista contemporánea Paula Rego representa las historias clásicas de una manera muy particular al ejercer cambios a las mismas dependiendo del mensaje a transmitir y la actualidad en la que se encuentra logrando así su propia versión de la historia "Si la historia está 'dada' me tomo libertades para adecuarla a mi propia experiencia y hacerla escandalosa" (p. 268). Su uso del color adquiere fuerza a través de la técnica y el mensaje que quiere transmitir. En la versión de Rego Blancanieves es identificada por sus colores (si cambiáramos el color de la vestimenta no identificaríamos a esta versión de doncella con Blancanieves), en su obra Snow White swallows the

${ }^{2}$ La manzana ha sido un referente histórico utilizado en diferentes historias como la de Adán y Eva, o la autora de la discordia entre las diosas Hera, Afrodita y Atenea. 
poisoned apple de 1995 (imagen 2), la autora utiliza el color como referente a una versión anterior creada por Disney de la misma historia, en este caso la transversalidad del color sirve como referente a la infancia representa por los colores en el vestido cuyo significado y referente con la niñez es adquirido cuando Disney muestra al mundo (1937) su versión de Blancanieves.

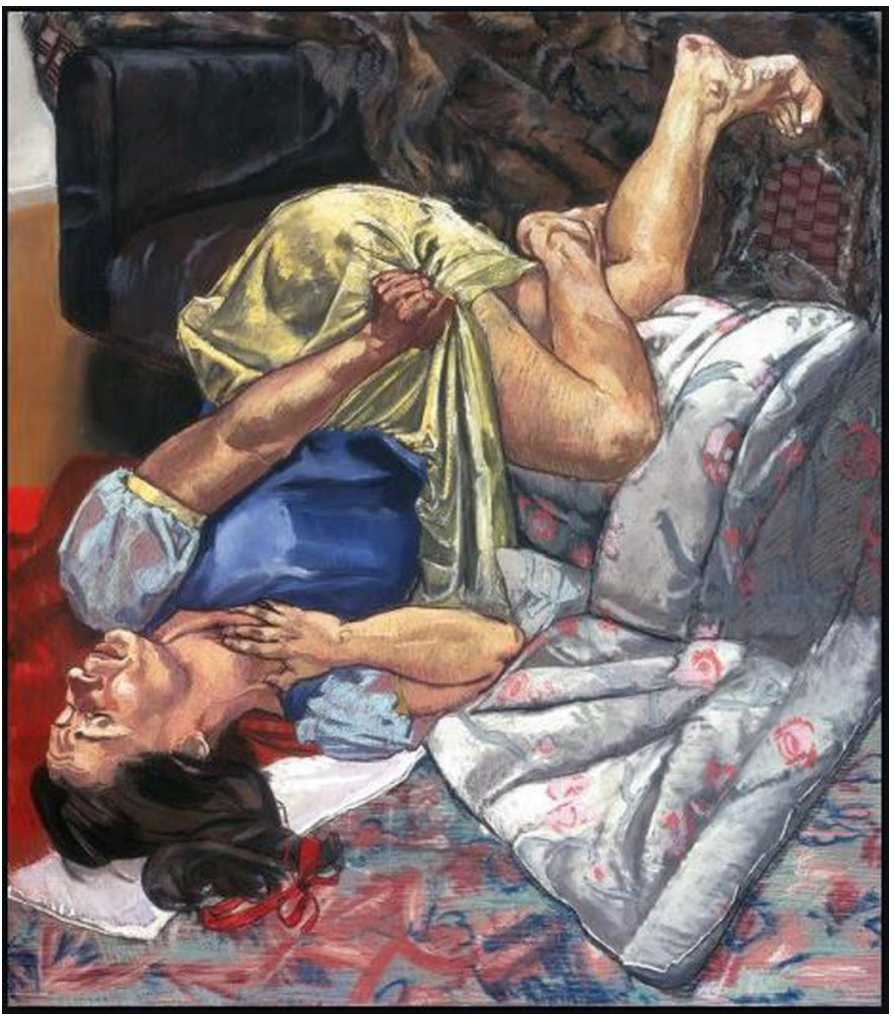

Figura 2. Tate Publishing, p. 80. (2007). Fuente: Imagen del libro Paula Rego de Fiona Bradley. 
En la versión de Rego el color no solo actúa como identificador de la historia de Disney, sino que además aporta un significado histórico a la imagen, lo que hace que ésta adquiera todo el sentido al reconocer que esa mujer del cuadro es Blancanieves, la niña inocente de Disney que, en la nueva versión de Rego, ya no lo es. El color actúa como signo-plástico donde sus características simbólicas y materiales actúan dotando de una narrativa profunda y significativa a la imagen.

\section{Conclusiones}

Al analizar el color en las imágenes de cuentos clásicos, su lectura como signo plástico es inevitable, no solo por su relación estética sino por la misma visualización expresiva de la misma, donde la lectura del color como signo genera inevitablemente una narrativa propia dentro de la imagen.

Existe una conexión entre el color manejada tanto en el texto como en la imagen que se mantiene como un identificador dentro de la misma, y por ende no solo nos muestra una característica cromática del objeto, sino que alimenta su significado sémico al relacionarlo con el texto.

Aunque existe una herencia del color de la literatura a la imagen, también y dependiendo del impacto y momento en que las imágenes se generan, la cromatología puede verse afectada determinado el modo en que se percibe la imagen; como es el caso de colores del vestido de Blancanieves con la versión de Disney en 1937, en el que se establecen ciertos colores como el amarillo, azul, rojo y blanco, como parte del vestido, (colores nunca mencionados en la historia original) introduciendo esta idea cromática en la cultura popular, hasta el punto de asociar esta combinación de colores en particular al personaje principal de la historia, dotándolo no solo de características identificativas sino simbólicas a través de los propios tonos, donde si se tiene en cuenta su lectura 
desde la psicología del color, podremos darnos cuenta que estos colores en particular terminan describiendo a la niña desde su personalidad y cambio evolutivo en la historia.

Al analizar el color en este tipo de ilustraciones es necesario concebirlo desde una visión activa, donde la percepción y lectura del color se relaciona no solo con los elementos adyacentes pertenecientes a la imagen sino que también se ve influenciado por los elementos contextuales e intertextuales de la historia, donde no es lo mismo ver una simple manzana en una imagen, a saber que es la misma que envenenó a Blancanieves, haciendo que el contexto cambie radicalmente nuestra visión de la misma.

Es necesario entender que, a pesar de la complejidad del estudio del color, el estudio de este debe darse a través y desde sus relaciones internas y externas que generan una conciencia de color entorno a sus conexiones y asociaciones haciendo ver y entender este elemento no como algo estático sino como algo activo que (dependiendo del manejo de sus cualidades, tono, luminosidad y saturación), puede cambiar en grado de influencia en la narrativa y entendimiento de la imagen.

\section{Referencias}

Barton, S. (2016). Graphic Storytelling and Visual Narrative: Images in Prose Fiction. In: Visual Devices in Contemporary Prose Fiction. London: Palgrave Macmillan.

Batchelor, D. (2000). Chromophobia. Reaction Books. London.

Becerra, J, Cotino Hueso, L., León, I.P., Sánchez-Acevedo, M.E., Torres Ávila, J. y Velandia Vega, J. (2018). Derecho y big data. Bogotá: Editorial Universidad Católica de Colombia. 
Berenger P. (Productor). (2012). Blancanieves. 1.35min. De https://www. youtube.com/watch?v=S9r_CZIQKwA.

Bettelheim, B. (2012). Psicoanálisis de los cuentos de hadas (Booket. divulgación, 3306). Barcelona: Editorial Crítica.

Becerra, J, Hernández, J y Pérez, N. (2019). Enseñando la Ley de Transparencia y acceso a la información pública con la ayuda de recursos electrónicos,331-342 ,Barcelona: Universitat Oberta de Catalunya, Huygens Editorial.

Carrere, A. y Saborit, J. (2000). Retórica de la pintura (Signo e imagen, 59). Madrid: Cátedra.

Gaster, M. (1931). Book review: The pentamerone of Giambattista Basile. Folklore, 42(4), 496-500.

Chirimuuta Mazviita 2017 Outside Color, Perceptual Sience and the Puzzle of color in Philosophy. The MIT Press, Cambridge, Massachusetts

Gombrich, E. (1994). Historia del arte. Barcelona, España: Ediciones Garrig.

Groupe $\mu$. (1993). Tratado del signo visual: para una retórica de la imagen. Madrid: Cátedra.

Grimm, J. \& Grimm, W. (1976). Cuentos / Jacob y Wilhelm Grimm, trad. Pedro Gálvez. Madrid: Alianza Editorial.

Grupo Mañana. (2016). Psicología Teórica, Neuropsicología del Color. Universidad de Granada.

Harthan, J. (1981). The history of the illustrated book. The western tradition. Thames and Hudson.

Heller, E. (2000). Psicología del color. Cómo actúan los colores sobre los sentimientos y la razón. Barcelona: Gustavo Gili. 
Revista KEPES, Año 17 No. 21, enero-junio de 2020, págs 171-194

Lee, K., Foster, J., \& Giles, R. (1968). Illustrators of children's Books 1957-1966. Boston: the horn book,INC.

Mavor, C. (2017). Aurelia: Art and Literature through the Mouth of the Fairy Tale London: Reaktion.

Nikolajeva, M. (2014). Retórica del personaje en la literatura para niños. México: Fondo de Cultura Económica.

Otálora K., \& Hernández J. (2018). ARTE Y DERECHO: DE LA PALABRA DEL PÜTCHIPÜ'ÜI A LA IMAGEN. Novum Jus, 12(1), 221-244. https://doi. org/10.14718/NovumJus.2017.12.1.9

Propp, V. (1984). Las raíces históricas del cuento (Cuarta edición. ed., Colección arte. serie crítica, 50). Madrid: Editorial Fundamentos.

St. Clair, K. (2016). The secret lives of color. New York: Penguin Books.

Zipes, J. (2014). El irresistible cuento de hadas: historia cultural y social de un genero. Ciudad Autónoma de Buenos Aires: Fondo de Cultura Económica.

Como citar: Hernández, J. (2020). La transversalidad del color y su papel comunicador en las imágenes visuales, de la literatura a la imagen actual del cuento clásico Blancanieves. Revista KEPES, 17 (21), 171-194. DOI: 10.17151/kepes.2020.17.21.7 